\title{
Monocyte Migration into the Subendothelial Space of a Coculture of Adult Human Aortic Endothelial and Smooth Muscle Cells
}

\author{
Mahamad Navab, ${ }^{\star}$ Gregory P. Hough, ${ }^{\star}$ Lynne W. Stevenson, ${ }^{\star}$ Davis C. Drinkwater, ${ }^{\ddagger}$ Hillel Laks, ${ }^{\ddagger}$ and Alan M. Fogelman \\ ${ }^{*}$ Division of Cardiology, Department of Medicine, and ${ }^{\ddagger}$ Division of Cardiothoracic Surgery, Department of Surgery, University of \\ California, Los Angeles School of Medicine, Los Angeles, California 90024
}

\begin{abstract}
Human aortic endothelial cells (EC) and smooth muscle cells (SMC) were isolated and used to form a multilayer of ECSMC separated by a layer of collagen. SMC and/or collagen layers exerted minimal effects on $\mathrm{Na}^{+}$transport but impeded the transport of LDL. The presence of an endothelial monolayer markedly reduced the transport of $\mathrm{Na}^{+}$and $\mathrm{LDL}$. When monocytes were presented to the complete coculture, in the absence of added chemoattractant, one monocyte entered the subendothelial space for every one to three EC present. In contrast, neither collagen nor SMC plus collagen nor EC plus collagen induced comparable monocyte migration. Despite massive migration of monocytes into the coculture, no significant alteration in $\mathrm{Na}^{+}$transport was observed. LDL transport into the preparation during massive monocyte migration increased modestly, but this was far less than the amount of LDL transported in the absence of an endothelial monolayer. We conclude that $(a)$ the endothelial monolayer was the principal permeability barrier, $(b)$ a substantial migration of monocytes occurred in the absence of added chemoattractant when both EC and SMC were present in the coculture, (c) endothelial barrier function was largely maintained after monocyte migration; and $(d)$ these experiments indicate the need to study all three cell types (monocytes, EC, and SMC) together to understand the complex interactions that occur between these cells.
\end{abstract}

\section{Introduction}

Investigation of the interactions that occur between the cells of the artery wall and blood components is essential to understanding normal vascular biology and the pathogenesis of such various conditions as atherosclerosis, tumor invasion, and inflammation. Such investigations, however, require appropriate techniques and systems, which several groups of investigators have attempted to establish. In all blood vessels except capillaries, endothelial (EC) ${ }^{1}$ and smooth muscle cells (SMC) coexist in close apposition. To study the interactions of vascular cells,

Address reprint requests to Dr. Mahamad Navab, Division of Cardiology, Department of Medicine, 47-123 CHS, UCLA School of Medicine, Los Angeles, CA 90024-1679.

Received for publication 15 January 1988 and in revised form 27 June 1988.

1. Abbreviations used in this paper: EC, endothelial cells; ER, electrical resistance; FBS, fetal bovine serum; IEL, internal elastic lamina; M199, medium 199; SMC, smooth muscle cells.

J. Clin. Invest.

(c) The American Society for Clinical Investigation, Inc.

$0021-9738 / 88 / 12 / 1853 / 11 \quad \$ 2.00$

Volume 82, December 1988, 1853-1863
Jones (1) cultured bovine EC on layers of rat SMC. Studies using this preparation indicated that the substratum had marked effects on the attachment and growth kinetics of EC (1). Merrilees and Scott (2) showed that the coculture of EC and SMC resulted in an increased production of hyaluronic acid and glycosaminoglycans as compared with the separate cultures of the two cell types. Using special coculture techniques, Davies and colleagues (3) demonstrated that EC-SMC interactions produced an increased receptor-mediated uptake and degradation of LDL by SMC. Hajjar et al. (4) reported that EC reduced cholesterol ester hydrolysis in cocultured SMC, compared with that in SMC cultured without EC. Moreover, the proliferation rate of SMC decreased by $50 \%$ in the coculture with EC (4). More recent studies by Hajjar and colleagues (5) have demonstrated that eicosanoids secreted from confluent EC significantly stimulated lysosomal cholesteryl esterase activity in cocultured SMC. Apparently, the state of EC growth and degree of confluence of EC on cocultured SMC can influence the modulation of cholesterol ester catabolism in cocultured SMC (5). Moving closer to reconstitution of a blood vessel in vitro, Weinberg and Bell have reported the development of a blood vessel model that reproduces many of the physical and biological characteristics of an artery (6). These investigators reported that their vessel model was able to withstand physiological pressure; the endothelial cell lining produced prostacyclin and $\mathrm{vWf}$ and functioned as a permeability barrier to albumin (6). However, because of the complexity of the model and the need to cannulate this model to perform metabolic experiments, the use of this model apparently has the same limitations as an isolated artery taken from an animal. The number of experiments thus is limited and there is as yet no evidence that repeated experiments on the same vessel are feasible.

Several in vitro systems have been designed to study the interaction and transport of blood components across endothelial monolayers. Taylor and colleagues (7) studied the interaction of neutrophils with endothelial monolayers grown on micropore filters. Shasby and colleagues (8) reported that granulocytes increased the movement of albumin across the EC monolayers by elaborating oxygen radicals. The increased permeability was reversible and depended on changes in EC shape and actin filaments which were related to EC calcium homeostasis (8). Territo et al. (9) reported that monocyte migration across EC monolayers produced increased LDL and albumin transport. Stoll and Spector (10) have demonstrated that fatty acids, including AA can be transferred between EC and SMC in coculture.

We have developed a coculture of human artery wall EC and SMC to study the early events of such chronic inflammatory processes as atherosclerosis. In this system, we are able to maintain and study the cells of adult human aorta together with extracellular matrix in various combinations, including 
that resembling the human artery wall, under different physiologic and pathologic conditions. We found that the major barrier to the passage of sodium ions and LDL across this coculture of human artery wall cells was the endothelial monolayer. We have been able to induce human monocytes to diapedese across the endothelial monolayer and enter the subendothelial space of this EC-SMC coculture. Based on both morphologic and biochemical data obtained from this model, we provide direct evidence that massive monocyte migration across the endothelium can occur without a substantial loss in endothelial barrier function. Furthermore, we demonstrate that all three cell types (monocytes, EC, and SMC) must be studied together to understand the complex interactions that occur between these cells.

\section{Methods}

Materials. Medium 199 (catalogue 12-117B; M199) was purchased from M. A. Bioproducts Inc., Walkersville, MD. HHF35, an anti-actin MAb (catalogue EAB-931) was obtained from Enzo Biochem, Inc., New York, NY. HAM56, a human macrophage-specific MAb was kindly provided by Dr. Allen Gown, University of Washington, Seattle, WA. Native collagen type I (catalogue C 3511) was purchased from Sigma Chemical Co., St. Louis, MO. Other materials and reagents were obtained from sources reported previously $(11,12)$.

Aortic cells. Human aortic EC and SMC were isolated from aortic specimens obtained from the heart donors ( $18 \pm 3 \mathrm{yr}$ old $)$ in our heart transplant program. A segment of the ascending aorta was dissected out and immediately placed in growth medium. This medium consisted of M199 containing 20\% fetal bovine serum (FBS), supplemented with $2 \mathrm{mM}$ L-glutamine, $1 \mathrm{mM}$ sodium pyruvate, $100 \mathrm{U} / \mathrm{ml}$ penicillin, and $100 \mu \mathrm{g} / \mathrm{ml}$ streptomycin. The aortic specimens were maintained in the growth medium supplemented with $20 \mu \mathrm{g} / \mathrm{ml} \mathrm{EC}$ growth factor and $90 \mu \mathrm{g} / \mathrm{ml}$ heparin and kept at $4^{\circ} \mathrm{C}$ until used. EC were isolated in a device developed for this purpose that allowed us to initially expose only the endothelium to enzymatic digestion. The device was constructed from polycarbonate and is composed of two plates. The bottom plate serves as a base and the top plate has openings of different diameters for specimens of various sizes. The aortic tissue was securely held between the two plates and the enzyme solution $(0.1 \% \mathrm{wt} / \mathrm{vol}$ collagenase in $\mathrm{M} 199)$ was introduced into the well that was formed over the endothelium. After three consecutive 10-min intervals at $37^{\circ} \mathrm{C}$, and dislodging of EC by a stream of $\mathrm{M} 199$ at the end of each interval, the cells were washed with M199 containing 10\% FBS (note that FBS used in media for washing and seeding of cells was not heat inactivated), and seeded in wells that were previously coated with $1 \%$ gelatin and treated with $1 \mu \mathrm{g} / \mathrm{cm}^{2}$ human fibronectin. The remaining EC were removed with a sterile cotton applicator and further digestion of the aortic specimen was carried out using the enzyme mixture described by Colucci et al. (13) for the isolation of SMC. Human aortic EC were identified by their typical cobblestone morphology, presence of Factor VIII-related antigen, and uptake of acetylated LDL labeled with 1,1'-dioctadecyl-1-3,3,3',3'-tetramethyl-indo-carbocyanine perchlorate (Dil-acetyl-LDL) (14). Human aortic SMC were identified morphologically and immunohistochemically using HHF35, which was then visualized by a fluorescently labeled second antibody or using a biotin-streptavidin complex immunoperoxidase system (15). EC were grown and propagated in the growth medium supplemented with heparin and EC growth supplement (16). SMC were grown in M199 containing 15\% FBS. The cells were passaged using a $0.1 \%$ solution of trypsin pH 7.2 containing 2 mM EDTA. Cells from passage levels 4-6 that had gone through 8-14 population doublings were used in the experiments reported here.

Human EC-SMC coculture. Using the cells obtained from aortas of our heart donors, we constructed a multilayer coculture of EC-collagen-SMC. In this model, polycarbonate filters with $1-\mu \mathrm{m}$-pore-diam and 13-mm-filter-diameter (catalogue 114010; Nucleopore Corp., Pleasanton, CA) were treated for 15 min with $70 \%$ ethanol, rinsed extensively in double-distilled water, and impregnated with gelatin by boiling for $30 \mathrm{~min}$ in a solution of $0.1 \%$ gelatin (catalogue G 2500; Sigma Chemical Co.) in PBS. The excess gelatin on the filters was removed by gently rinsing in PBS, and the filters were placed on top of wells in a 48-well tissue culture plate and were dried at $60^{\circ} \mathrm{C}$ for 30 $\min$. The filters were gas-sterilized with ethylene oxide, thoroughly aired to remove the residual ethylene oxide, and assembled in the U-shaped chambers of a transport device forming separate compartments on each side of the filter (11). Because of the gaskets holding the filters in place, the surface area available for seeding cells on each filter was $0.71 \mathrm{~cm}^{2}$. Human aortic SMC in M199 containing 15\% FBS were seeded on filters at a density of $1.5 \times 10^{5}$ cells $/ \mathrm{cm}^{2}$ and allowed to grow for $\mathbf{2} \mathrm{d}$, at which time they covered the entire surface of the filter. The wells on the basal side of the SMC multilayer (the side of the filter without cells) were closed with a special plug developed for this purpose and the units were placed on their side, bringing the filters with the SMC layers to a horizontal position. The medium above the SMC was removed, the cell layer was washed with M199, and 10 or $25 \mu \mathrm{l}$ of a solution of native collagen type I $(0.2 \% \mathrm{wt} / \mathrm{vol})$ was layered over the SMC. The collagen layer was allowed to polymerize and form a gel at $37^{\circ} \mathrm{C}$ for $30 \mathrm{~min}(17)$. The collagen layer was subsequently treated with a solution of human fibronectin $\left(20 \mu \mathrm{g} / \mathrm{cm}^{2}\right)$ for $2 \mathrm{~h}$ at $37^{\circ} \mathrm{C}$. The excess fibronectin was washed away with M199 and human aortic EC in M199 containing 20\% FBS were seeded on the collagen layer at a density of $2.5 \times 10^{5}$ cells $/ \mathrm{cm}^{2}$. After $3 \mathrm{~h}$ of incubation at $37^{\circ} \mathrm{C}$, the EC had attached to the collagen surface, the cells were gently washed with M199 containing 10\% FBS, and the units were placed upright. The plugs were removed from the basal side, complete growth medium was placed in the wells on both sides of the filter, and EC were allowed to grow and cover the entire surface of the collagen layer. After 24-48 h, the electrical resistance across the multilayers was determined using an electrode and measuring system described previously (11). Only preparations with an electrical resistance (ER) of $>12 \Omega \cdot \mathrm{cm}^{2}$ were used for these experiments, and hence a confluent endothelial monolayer was always present over the entire coculture.

$L D L$ transport. Human LDL was isolated from the sera of fasting human donors by sequential ultracentrifugation at $d=1.019-1.063$ $\mathrm{g} / \mathrm{ml}(18)$. Iodination of LDL was performed by the method of McFarlane (19) as modified by Bilheimer et al. (20). The concentration of each lipoprotein is given as the protein concentration determined by the method of Lowry et al. (21). Study of the transport of human ${ }^{125} \mathrm{I}-\mathrm{LDL}(60,000 \mathrm{cpm} / \mu \mathrm{g})$ into the EC-SMC coculture was carried out as follows: a solution of ${ }^{125}$ I-LDL $(100 \mu \mathrm{g} / 150 \mu \mathrm{l})$ in M199 containing $10 \%$ heat-inactivated FBS (M199-FBS) was placed on the endothelial side of the multilayer in the well above the filter with the unit on its side; the well below the filter had previously been plugged and contained the same medium as that in the upper well but without added LDL. After $90 \mathrm{~min}$ in a $37^{\circ} \mathrm{C}$ incubator, the ER across the filter was determined and the media on both sides of the filter were removed and saved for LDL determination. The multilayers were washed twice with $1 \mathrm{ml}$ of $\mathrm{M} 199$ at $37^{\circ} \mathrm{C}$ and were used for biochemical or histologic studies. For quantitation of LDL, the multilayers were scraped from the filters and were transferred to microfuge tubes in $0.5 \mathrm{ml}$ of M199 containing $10 \%$ bovine serum. After $5 \mathrm{~min}$ of vigorous homogenization, the TCA-precipitable ${ }^{125}$ I radioactivity was determined.

Monocyte migration. Human blood monocytes were obtained by counterflow centrifugation as described by Fogelman and associates (22) or by a modification of the procedure of Recalde (23). For migration studies, $5 \times 10^{5}$ monocytes were presented to the endothelial side of the multilayer (containing $25 \mu \mathrm{l}$ of added collagen and with the unit on its side and filter and multilayer in a horizontal position) in the presence or absence of a gradient of the chemotactic factor FMLP added at a concentration of $1 \times 10^{-8} \mathrm{M}$. This concentration of FMLP was chosen after study of monocyte chemotaxis across human endothelial monolayers on filters in response to concentrations of FMLP ranging from $1 \times 10^{-9}$ to $1 \times 10^{-6} \mathrm{M}$. The concentration of $1 \times 10^{-8} \mathrm{M}$ 
was found to produce the maximum directed migration of monocytes (data not shown). To determine the role of each component of the multilayer in the migration of monocytes in the absence of added chemoattractant, the following preparations were prepared and studied: $(a)$ a layer of collagen alone $(25 \mu \mathrm{l})$ on filter, $(b)$ SMC grown on a filter and covered with a layer of collagen, $(c)$ an EC monolayer grown on a layer of collagen previously formed on a filter, and $(d)$ the complete multilayer composed of SMC grown on a filter covered with a layer of collagen with an EC monolayer grown on top of the collagen layer. For quantitation of monocyte migration, the preparations were embedded in paraffin and 4- $\mu \mathrm{m}$ transverse sections were prepared as described below (see Histology). The sections were treated with HAM56 stained with an avidin-biotin immunoperoxidase system (15), and counted under 400 or 1,000 magnification in randomly selected fields from each condition. Statistical significance was determined using the $t$ test. A $P$ value of $<0.05$ was considered significant.

Histology. The preparation on each filter was washed with Tyrode's solution at $37^{\circ} \mathrm{C}$ and then fixed in a solution of $10 \%$ neutral buffered formalin or a solution of $1 \%$ glutaraldehyde in Tyrode's buffer for 15 min at $37^{\circ} \mathrm{C}$. After dehydration in graded alcohol solutions of 10 to $100 \%$, the preparations were embedded in paraffin or in Spurr (24).

\section{Results}

Human EC-SMC coculture. A multilayer of human aortic SMC grown on a micropore filter was covered with a gel layer of native collagen and a monolayer of human aortic EC was grown on top of the collagen layer. As demonstrated in Fig. 1 $A$, the thick collagen layer, resembling the internal elastic lamina (IEL) in large arteries (25), separated the SMC layers from the endothelial monolayer that expressed Factor VIII-related antigen (Fig. $1 \mathrm{~B}$ ). The transverse section shown in Fig. $1 \mathrm{C}$ depicts a preparation in which a smaller volume of collagen (10 vs. $25 \mu \mathrm{l}$ for $A$ and $B$ ) was layered over the SMC, producing a thinner collagen layer between the EC and SMC resembling the IEL in small elastic arteries (25). Exposure of this coculture to human monocytes resulted in monocyte attachment to the EC (Fig. 2) followed by monocyte migration across the endothelial monolayer into the collagen layer of the subendothelial space (Fig. $2 C$ ). The monocytic nature of the leukocytes that attached to the EC and migrated into the subendothelial space was confirmed with a MAb to the human monocyte-macrophage HAM56 (15). As noted by Gown and co-workers (15), HAM56 also reacted slightly with some of the EC (Fig. $2 C$ ). After the exposure of $5 \times 10^{5}$ monocytes to the multilayer for $90 \mathrm{~min}$ in the absence of added chemotactic factor (FMLP), $1.1 \pm 0.3 \times 10^{5}$ monocytes migrated across the endothelial monolayer into the collagen layer (Fig. 3 ). This was $38 \%$ of the maximum monocyte migration $\left(2.8 \pm 0.4 \times 10^{5}\right.$ cells $\left./ 90 \mathrm{~min}\right)$ induced by a gradient of FMLP added at a concentration of 1 $\times 10^{-8} \mathrm{M}$ (Fig. 3). The number of monocytes that entered the subendothelial space made up $22 \pm 6$ and $57 \pm 8 \%$ of the $5 \times 10^{5}$ monocytes that were presented to the endothelial side of the preparation in the absence or presence of FMLP, respectively.

To determine the role of each component of the coculture in the migration of monocytes in the absence of added chemoattractant, the experiments shown in Fig. 4 were performed. Collagen alone had a minimal effect on monocyte migration; only $0.81 \pm 0.76 \%$ of the added monocytes entered the collagen layer. SMC plus collagen or EC plus collagen induced only $2.79 \pm 1.88$ and $1.98 \pm 1.91 \%$ of monocytes to migrate into the collagen layer, respectively. However, EC and SMC together with collagen induced $11.18 \pm 4.07 \%$ of the monocytes to migrate into the subendothelial space of the multilayer preparation (Fig. 4). The experiments in Fig. 4 represent the mean $\pm 1 \mathrm{SD}$ of values obtained in four separate experiments. In these experiments, which were conducted in the absence of added chemoattractant, one monocyte migrated into the subendothelial space for every two to three EC present in the preparations containing EC and SMC together with collagen. In four out of four of these experiments, the monocyte migration induced by the preparations containing EC and SMC together with collagen was greater than the sum of that induced by EC and collagen plus that induced by SMC and collagen.

Permeability studies. The human aortic EC grew and formed a monolayer on polycarbonate filters and developed a peak electrical resistance (ER) of $14.2 \pm 1.6 \Omega \cdot \mathrm{cm}^{2}$ at confluence. As previously demonstrated, ER is an excellent measure of sodium ion transport (11). SMC seeded on micropore filters grew to confluence and formed multilayers covering the entire surface of the filter. The SMC multilayers did not produce a significant impediment to the movement of small ions such as $\mathrm{Na}^{+}$, as indicated by the low ER of $3.1 \pm 0.6 \Omega \cdot \mathrm{cm}^{2}$. However, the SMC multilayers partially inhibited the transport of LDL, as 2,048 $\pm 81 \mathrm{ng} \mathrm{LDL} / 90 \mathrm{~min}$ was transported across the SMC multilayer on the filter to the basal compartment, compared with $14,030 \pm 1,048 \mathrm{ng} \mathrm{LDL} / 90 \mathrm{~min}$ transported across filters without cells or collagen. Collagen alone $(25 \mu$ l) on filters without cells did not present a significant barrier to the transport of $\mathrm{Na}^{+}$as measured by ER $(0.31 \pm 0.2$ $\left.\Omega \cdot \mathrm{cm}^{2}\right)$. The collagen layer in the absence of cells accumulated significant amounts of LDL and markedly reduced the transport of LDL from one side of the filter to the other. Large quantities $(6,039 \pm 475 \mathrm{ng})$ of LDL were contained in the collagen layer and 1,820 $\pm 178 \mathrm{ng} \mathrm{LDL} / 90 \mathrm{~min}$ was transported across filters with collagen (without cells). In other experiments, the LDL content of collagen layer was determined to be proportional to the amount of collagen added in the multilayer. The presence of $25 \mu \mathrm{l}$ of collagen on the filter thus resulted in the retention of $6,590 \pm 951 \mathrm{ng}$ of LDL, compared with $3,650 \pm 491 \mathrm{ng}$ of LDL retained by $10 \mu \mathrm{l}$ of collagen gel. The presence of EC on the collagen layer increased the ER of the preparation by threefold (from $4.8 \pm 1.0$ to $14.2 \pm 1.7$ $\Omega \cdot \mathrm{cm}^{2}$ ). Monocyte diapedesis across the EC monolayer along a gradient of the chemoattractant FMLP added at a concentration of $1 \times 10^{-8} \mathrm{M}$ did not significantly change the transport of $\mathrm{Na}^{+}$, as indicated by a lack of significant alteration in ER $\left(14.6 \pm 1.3\right.$ and $12.9 \pm 1.8 \Omega \cdot \mathrm{cm}^{2}$ before and after monocyte diapedesis, respectively). The presence of the endothelial monolayer produced a 47 -fold reduction in the LDL content of the collagen layer (from 6,039 \pm 475 to $128 \pm 19 \mathrm{ng} \mathrm{LDL} / 25$ $\mu \mathrm{g}$ of collagen gel, Fig. 5). The amount of LDL that was transported across the endothelial monolayer and was retained by the collagen layer increased significantly, from $128 \pm 19$ to $251 \pm 31 \mathrm{ng} \mathrm{LDL} / 25 \mu \mathrm{g}$ of collagen gel, $P<0.001$, when monocytes were induced to diapedese across the endothelial monolayer by a gradient of FMLP added at a concentration of 1 $\times 10^{-8} \mathrm{M}$ (Fig. 5). This concentration of FMLP had been determined to induce maximal migration of human monocytes across a monolayer of human aortic EC on filters (data not shown). Note that the increase in the LDL content of the collagen layer produced by monocyte transmigration in response to FMLP, was very small compared with the LDL content of the collagen layer in the absence of the endothelial monolayer $(6,039 \pm 475 \mathrm{ng} \mathrm{LDL} / 25 \mu \mathrm{g}$ of collagen gel, Fig. 5). 


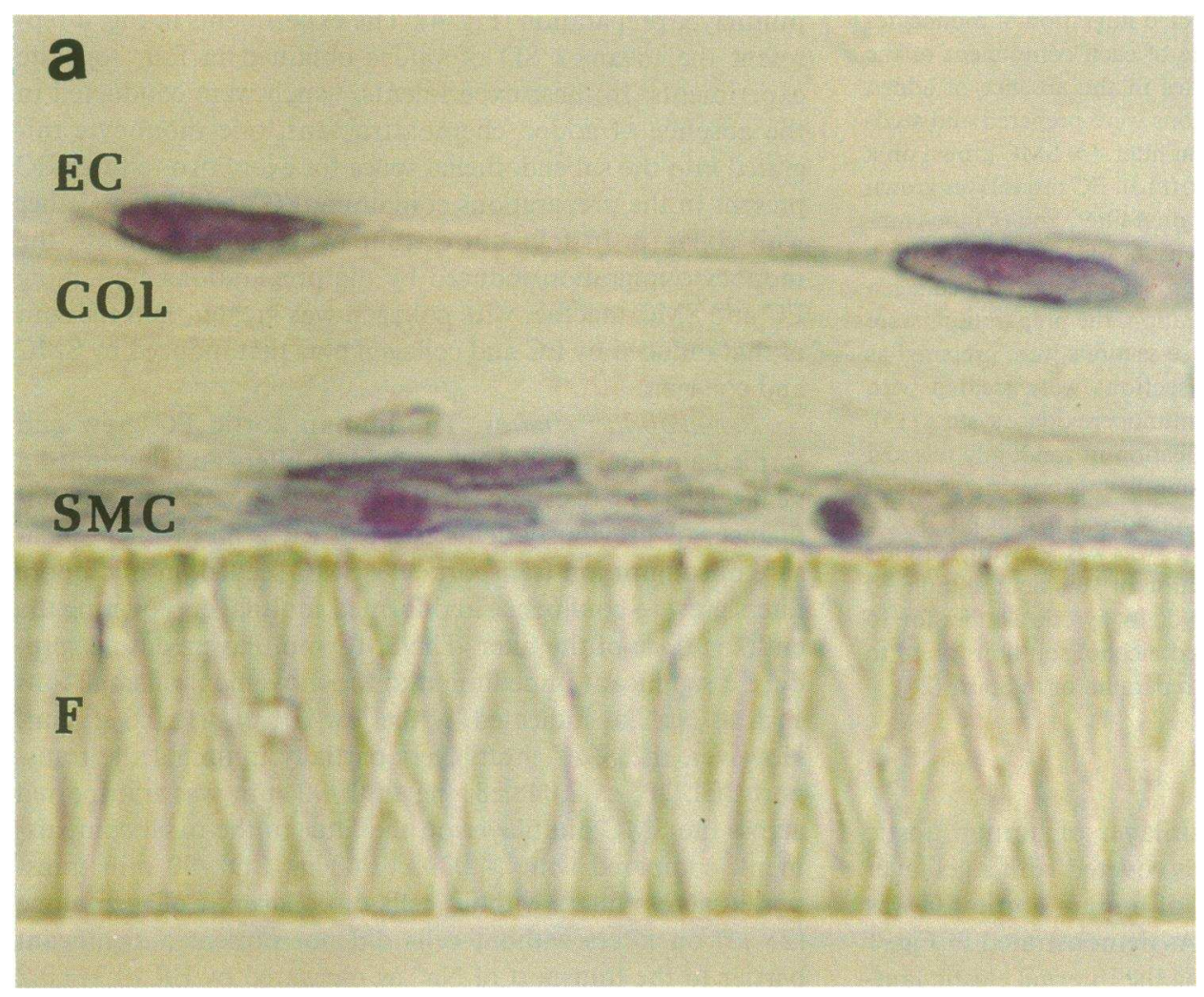

Figure 1. Coculture of human aortic EC and SMC. Human aortic SMC were seeded at a density of 1.5 $\times 10^{5}$ cells $/ \mathrm{cm}^{2}$ on a polycarbonate filter $(F)$ with $1-\mu \mathrm{m}$ pores as described in Methods. After $2 \mathrm{~d}$ of SMC growth, the cells were covered with $10(C)$ or $25 \mu \mathrm{l}(A$ and $B)$ of a solution of native collagen type I ( $0.2 \% \mathrm{wt} / \mathrm{vol}$ in M199), which was allowed to polymerize at $37^{\circ} \mathrm{C}$ for $30 \mathrm{~min}$. The gel surface was subsequently treated with a solution of fibronectin $\left(20 \mu \mathrm{g} / \mathrm{cm}^{2}\right)$ and human aortic EC were seeded on top of the collagen layer $(\mathrm{COL})$ at a density of $2.5 \times 10^{5} \mathrm{cells} / \mathrm{cm}^{2} . A$ and $C$ show $1-\mu \mathrm{m}$ transverse sections of Spurr embedded preparations stained with toluidine blue-basic Fuchsin.

$\times 4,000$ and $\times 1,500$, respectively.

(B) A transverse section of a paraffin-embedded human EC-SMC preparation stained with a fluoresceinated goat anti-human Factor VIII-related antigen. $\times 4,800$. The figure shows a confluent human aortic EC monolayer and a SMC multilayer separated by a layer of collagen. The EC monolayer expressed Factor VIII-related antigen $(B)$.

\section{EC}

$\mathrm{COL}$

\section{SMC}




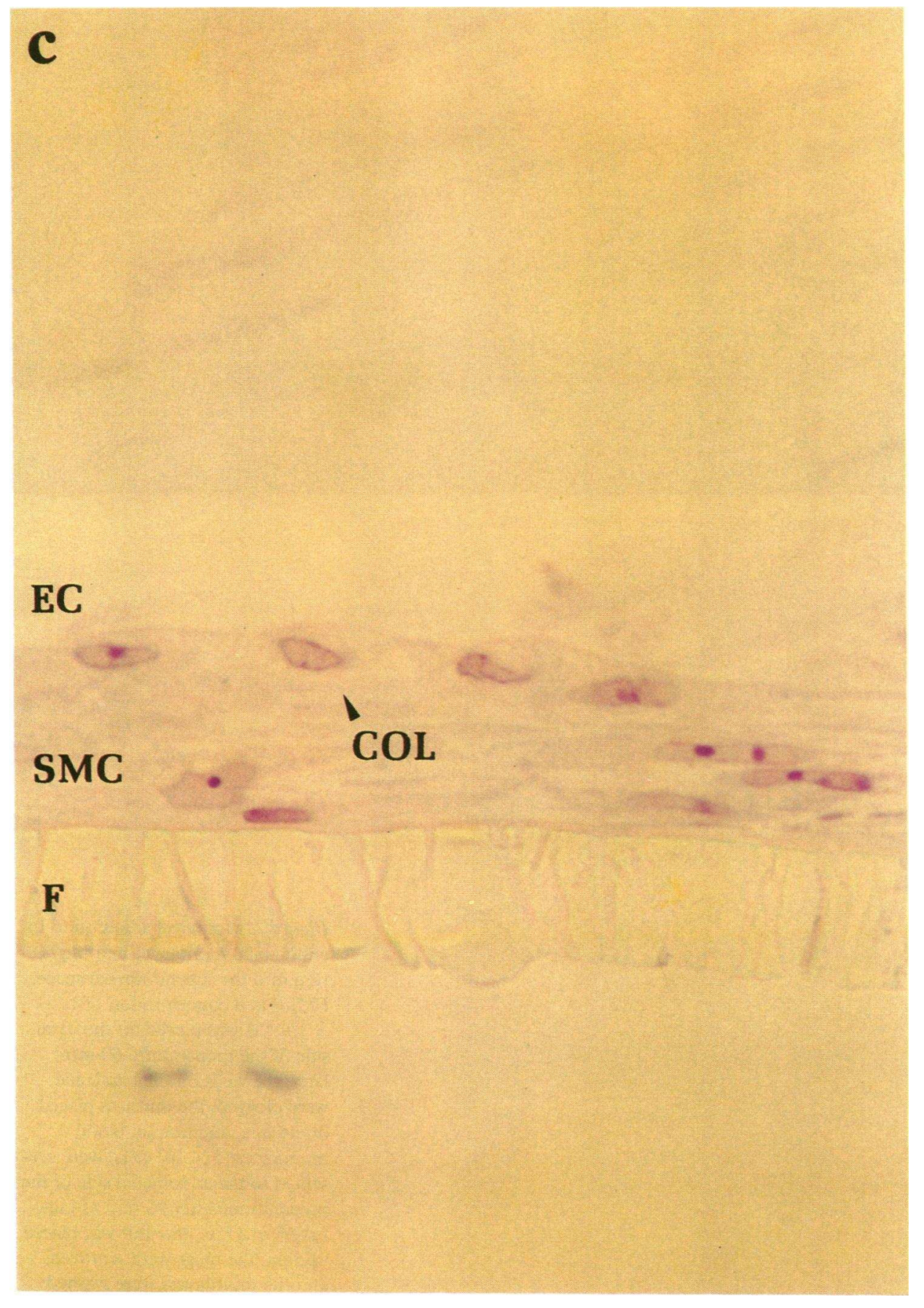

Figure 1 (Continued)

The presence of FMLP on the basal side without monocytes on the endothelial side did not produce an increase in the LDL content of the collagen layer. Exposure of the multilayer to monocytes in the absence of added FMLP did not result in a significant increase in the LDL content of the collagen layer (Fig. 5), despite a marked monocyte migration (Figs. 2 and 4). The amount of LDL transported across the preparations is shown in Fig. 6. The data in Fig. 6 demonstrate that the presence of the endothelial monolayer reduced the amount of the transported LDL by 10 -fold (from $1,820 \pm 178$ to $180 \pm 51 \mathrm{ng}$ LDL/90 min). Monocyte migration induced by FMLP produced a modest $63 \%$ increase in LDL transport across the EC-SMC multilayer (from $180 \pm 51$ to $294 \pm 48 \mathrm{ng}$ LDL/90 min, $P<0.001$, Fig. 6 ). The transport of LDL was not significantly altered when FMLP or monocytes alone were present (Fig. 6).

\section{Discussion}

The in vitro system that we report here allows culture of the cells of the human adult aorta together with extracellular matrix in various combinations, including that resembling the human artery wall. In contrast to the Weinberg and Bell model (6), this system easily permits repeated measurements on many preparations. We observed that the endothelial monolayer was the primary barrier to the transport of sodium ions 

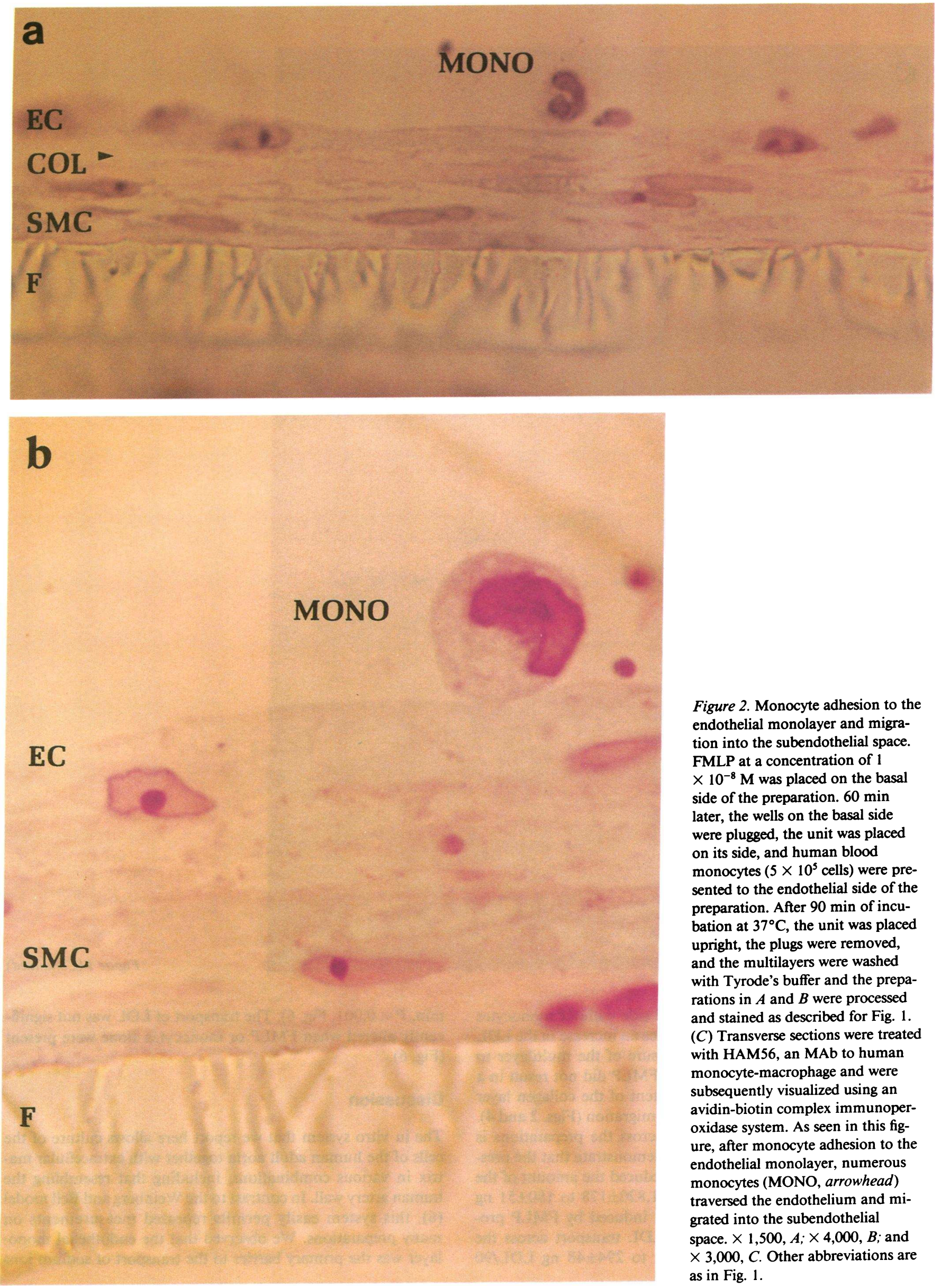

Figure 2. Monocyte adhesion to the endothelial monolayer and migration into the subendothelial space. FMLP at a concentration of 1 $\times 10^{-8} \mathrm{M}$ was placed on the basal side of the preparation. $60 \mathrm{~min}$ later, the wells on the basal side were plugged, the unit was placed on its side, and human blood monocytes $\left(5 \times 10^{5}\right.$ cells) were presented to the endothelial side of the preparation. After $90 \mathrm{~min}$ of incubation at $37^{\circ} \mathrm{C}$, the unit was placed upright, the plugs were removed, and the multilayers were washed with Tyrode's buffer and the preparations in $A$ and $B$ were processed and stained as described for Fig. 1

(C) Transverse sections were treated with HAM56, an MAb to human monocyte-macrophage and were subsequently visualized using an avidin-biotin complex immunoperoxidase system. As seen in this figure, after monocyte adhesion to the endothelial monolayer, numerous monocytes (MONO, arrowhead) traversed the endothelium and migrated into the subendothelial space. $\times 1,500, A ; \times 4,000, B$; and $\times 3,000, C$. Other abbreviations are as in Fig. 1. 


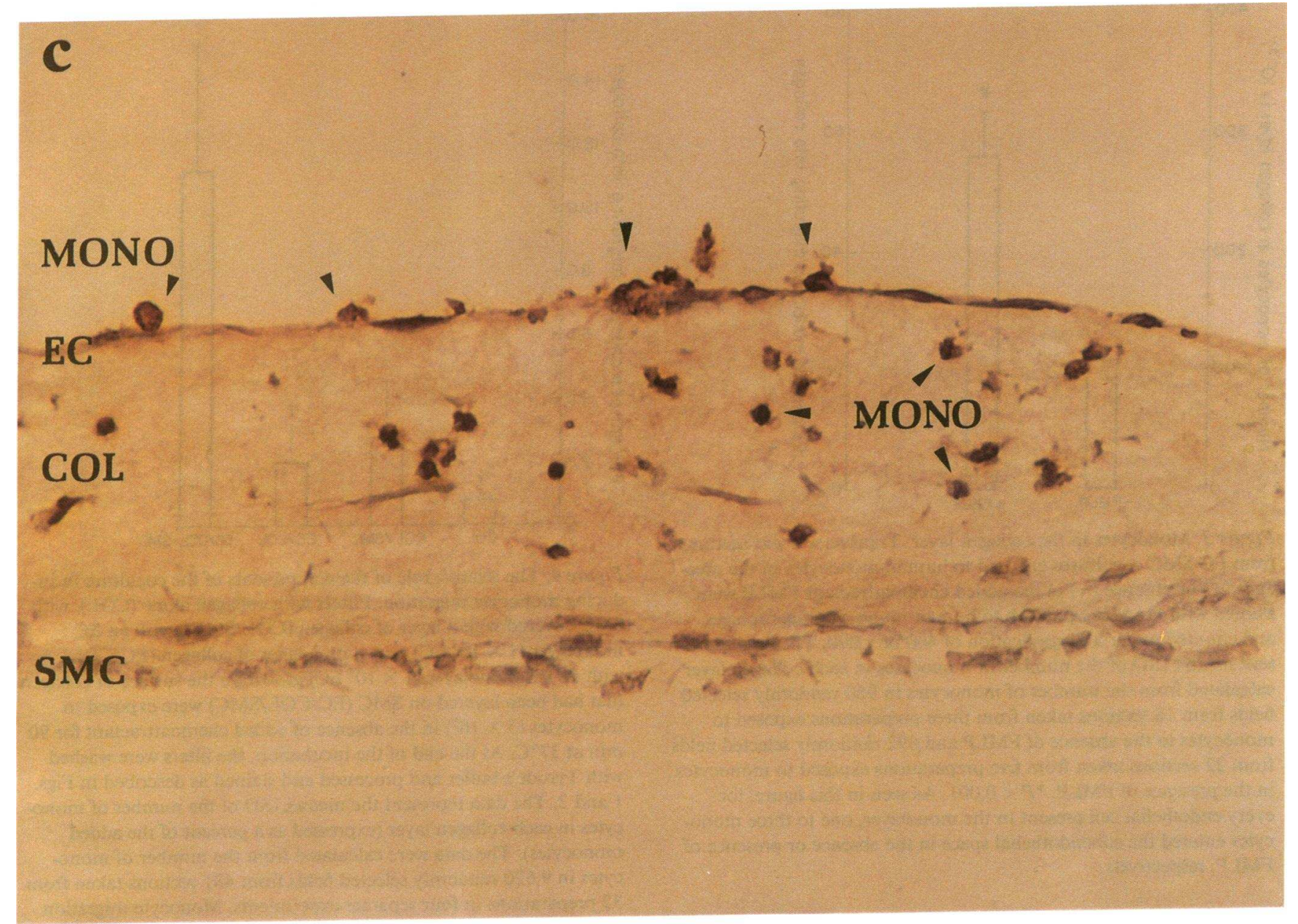

Figure 2 (Continued)

and LDL, whereas the collagen layer selectively reduced the movement of LDL but not that of sodium ions. Several groups of investigators have demonstrated that the vascular endothelium is the primary barrier to the transport of various molecules into the vessel wall (26-28). Chobanian and colleagues (27) reported that the removal of rabbit carotid artery endothelium induced a 10 -fold increase in permeability to ${ }^{125} \mathrm{I}$-albumin and a threefold increase in the transport of $\left[{ }^{3} \mathrm{H}\right] 3$-methylD-glucose into the artery wall. Ramirez et al. (28) found that the removal of rabbit aortic endothelium increased the concentration of tracer ${ }^{125} \mathrm{I}$-albumin in the medial layer 10-40fold. O'Donnell and Vargas (29) determined the hydraulic conductivity and the ER of rabbit aortas before and after detergent removal of the endothelium and found that the endothelium contributed $>50 \%$ of the total artery wall ER $\left(9.7 \pm 4.1\right.$ and $18.4 \pm 6.5 \Omega \cdot \mathrm{cm}^{2}$, respectively). These ER values are remarkably similar to those reported in this study of human cells, as well as that previously reported for cultured rabbit aortic endothelial cells $(11,12)$.

Work from several laboratories has shown that there is a strong attraction between human monocytes and endothelial cells in culture (30-32). Pawlowski and colleagues (30) reported a high degree of attachment of monocytes (8-10 monocytes per EC) after $60-90 \mathrm{~min}$ of incubation at $37^{\circ} \mathrm{C}$. Miglior- isi and colleagues (32) reported that when they incubated human monocytes with human umbilical vein $\mathrm{EC}, \sim 10 \%$ of the monocytes migrated across the EC monolayer in the absence of an added chemotactic factor. This value increased to 25-35\% when they produced a chemotactic gradient by addition of leukotriene $B_{4}$ or FMLP to the basal side of the endothelial monolayer (32). Furie and colleagues recently studied neutrophil migration across monolayers of EC (33). After 1-2 $h$ of incubation, $29 \pm 12 \%$ of the neutrophils emigrated through the endothelial monolayer grown on human amnion connective tissue.

More than two decades ago, Florey and Grant (34), Still and Marriott (35), and Geer (36) presented evidence for the possible role of monocytes in the development of the atherosclerotic lesion. A decade later, Gerrity and colleagues reported that monocyte invasion of the subendothelial space was the earliest cellular event in the development of atherosclerotic lesions in cholesterol-fed swine (37). Subsequently, Ross and colleagues confirmed that monocyte invasion of the intima was the earliest cellular event in monkeys and rabbits on an atherogenic diet (38). In all these studies, by morphologic criteria, the integrity of the endothelium appeared to be initially maintained despite a massive monocyte migration into the subendothelial space. 


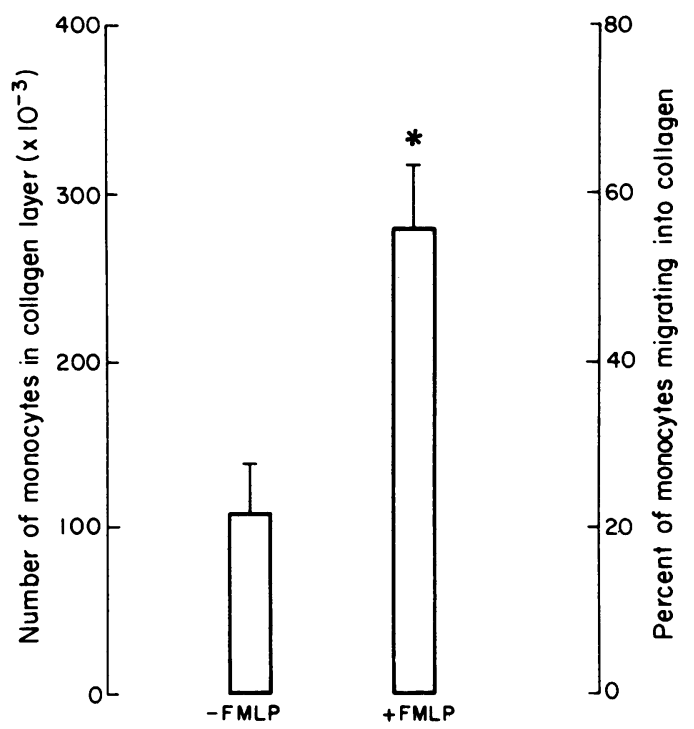

Figure 3. Monocytes in the collagen layer. Transverse 4- $\mu \mathrm{m}$ sections from EC-SMC cocultures exposed to human monocytes in the presence $(+)$ or absence $(-)$ of the added chemoattractant FMLP were stained with HAM56, an MAb to human monocyte-macrophage, and counted under a magnification of 400 or 1,000 . The data represent mean $\pm 1 S D$ of the number of monocytes in each collagen layer calculated from the number of monocytes in 960 randomly selected fields from 18 sections taken from three preparations exposed to monocytes in the absence of FMLP and 692 randomly selected fields from 22 sections taken from five preparations exposed to monocytes in the presence of FMLP. ${ }^{*} P<0.001$. As seen in this figure, for every endothelial cell present in the monolayer, one to three monocytes entered the subendothelial space in the absence or presence of FMLP, respectively.

In this study, a massive monocyte migration (one to three monocytes per EC) into the EC-SMC coculture occurred without a substantial loss of endothelial barrier function. The mechanism of leukocyte migration across the endothelium remains to be explained, but regardless of the path taken, monocyte migration does not seem to severely disrupt the endothelium. Furie et al. (33) reported that morphologically close contacts persisted between neutrophils and EC throughout migration. The contacts between EC and migrating neutrophils nearly always appeared intact. Nash and colleagues (39) have reported on the transmigration of neutrophils across a monolayer of the epithelial cell line $T_{84}$, which produces a very high ER $\left(1,100 \Omega \cdot \mathrm{cm}^{2}\right)$. At low neutrophil/epithelial cells ratios (1:10), there was no significant alteration of the ER after neutrophil migration (39). Moreover, the ER reduction observed when high neutrophil densities (10 for each epithelial cell) were used was reversed in $<24 \mathrm{~h}$ (39).

When human monocytes were added to the endothelial side of the EC-SMC coculture, a substantial migration of monocytes into the subendothelial space occurred in the absence of added chemoattractant (Fig. 3). The induction of monocyte migration in the absence of added chemoattractant is consistent with the presence of endogenous factors chemotactic for monocytes. Berliner and colleagues (40) have demonstrated that rabbit aortic and human carotid artery EC in culture produce chemotactic factor(s) for human blood monocytes. Jauchem and colleagues showed that baboon arterial

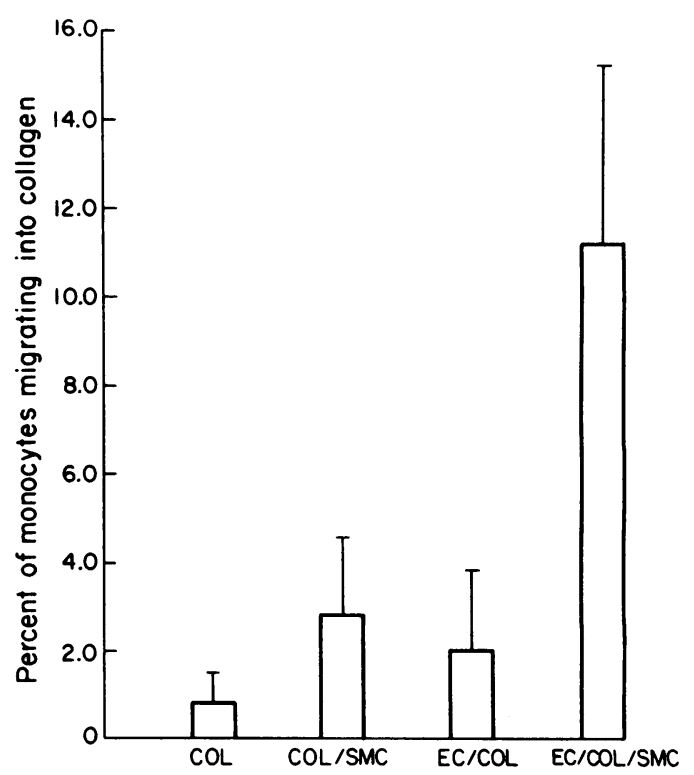

Figure 4. The relative role of the components of the coculture in inducing monocyte migration. Filters with collagen alone (COL), with SMC covered with a layer of collagen (COL/SMC), with an EC monolayer $\left(1 \times 10^{5} \mathrm{EC}\right)$ grown on a layer of collagen $(\mathrm{EC} / \mathrm{COL})$, or with an EC monolayer $\left(1 \times 10^{5} \mathrm{EC}\right)$ grown on the surface of collagen that had been layered on SMC (EC/COL/SMC) were exposed to monocytes $\left(5 \times 10^{5}\right)$ in the absence of added chemoattractant for 90 $\min$ at $37^{\circ} \mathrm{C}$. At the end of the incubation, the filters were washed with Tyrode's buffer and processed and stained as described in Figs. 1 and 2 . The data represent the mean \pm ISD of the number of monocytes in each collagen layer (expressed as a percent of the added monocytes). The data were calculated from the number of monocytes in 9,620 randomly selected fields from 481 sections taken from 32 preparations in four separate experiments. Monocyte migration induced by $\mathrm{EC} / \mathrm{COL} / \mathrm{SMC}$ was significantly greater than that induced by COL, COL/SMC or EC/COL $(P<0.001)$.

SMC secreted monocyte chemotactic activity in culture (41). Mazzone and colleagues (42) demonstrated that cultured human aortic SMC are capable of producing a potent factor chemotactic for monocytes. Our observation that migration of monocytes stimulated by FMLP produced a small but signifcant increase in the LDL content of the collagen layer and in elevated levels of LDL on the basal side of the multilayer is consistent with the findings of Territo and colleagues (9). We cannot exclude the possibility that the increased collagen LDL content resulted from the entry of LDL associated with monocytes as they entered the collagen layer. However, as the monocyte could not cross the filter (1- $\mu \mathrm{m}$ pores), the LDL would have had to be released from the monocytes within the collagen layer to explain the increased LDL concentration on the basal side (Fig. 6). Despite the substantial monocyte migration in the absence of FMLP, there was no significant increase in LDL transport. FMLP alone had no effect on LDL transport, indicating that the increased LDL transport in the presence of FMLP required a monocyte-EC interaction. The finding that the combination of both EC and SMC was required to induce a substantial monocyte migration into the subendothelial space in the absence of added chemoattractant indicates the need to study all three cell types (monocytes, EC, and SMC) 


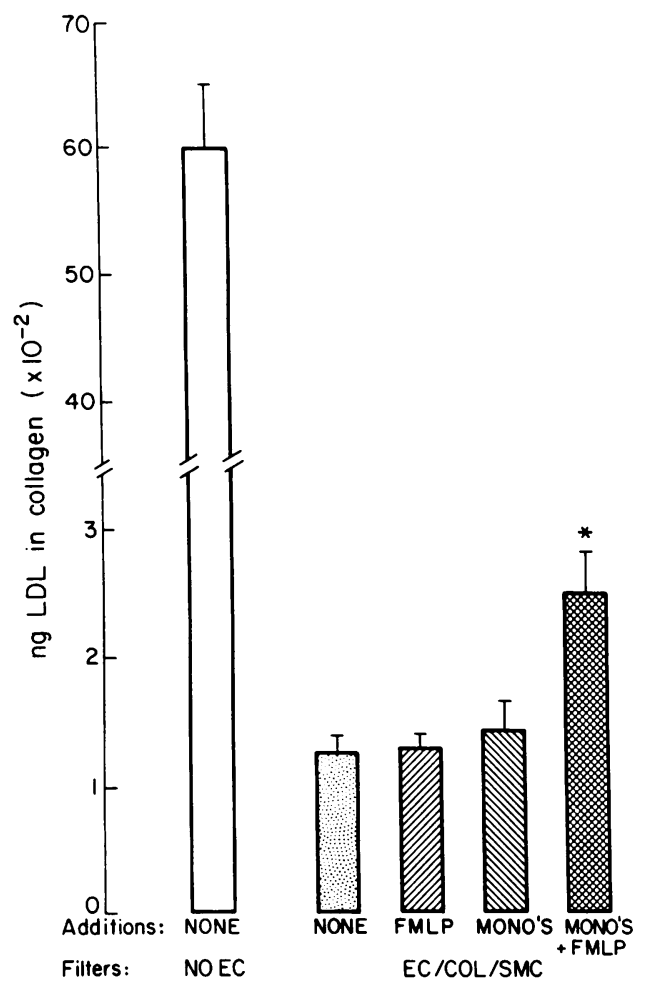

Figure 5. LDL content of the collagen layer as a function of monocyte migration. After $90 \mathrm{~min}$ of exposure to monocytes and LDL, the preparations were washed with M199 and were scraped from the filters, transferred to microfuge tubes and homogenized and TCAprecipitable ${ }^{125}$ I-radioactivity was determined. Radioactivity precipitated from preparations containing EC alone and SMC alone were subtracted from the values obtained from preparations with all three layers $(\mathrm{EC} / \mathrm{COL} / \mathrm{SMC})$ to obtain the LDL content of the collagen layer. Data represent mean $\pm 1 \mathrm{SD}$ of values from 4-16 preparations. ${ }^{*} P<0.001$. EC/COL/SMC, a multilayer of smooth muscle cells grown on a filter, covered with a layer of collagen with an endothelial monolayer grown on the surface of the collagen layer; MONO'S, monocytes. Whereas the increase in LDL content of the collagen layer was statistically significant after monocyte diapedesis, the absolute amount of the increase was very small compared with the LDL content of collagen in the absence of an endothelial monolayer.

together to understand the complex interactions that occur between these cells.

Diapedesis of monocytes through the wall of large vessels appears to be a normal, continuous event, as demonstrated by Joris and colleagues, who observed the presence of one subendothelial monocyte per nine EC in rat aorta (43). Freudenberg and Riese (44) found that $10 \%$ of all the cells in the endothelium of rat aorta were white blood cells, with monocytes accounting for $80 \%$ of the leukocytes. In normal swine, Gerrity and associates (37) found mononuclear cells adherent to the endothelium in $17-23 \%$ of the sections and found mononuclear cells in the subendothelial space in $4 \%$ of sections taken from sites of predilection (areas of increased permeability). Monocyte-like cells have also been seen in normal rabbit aorta (45) and normal human aorta (36). In the two studies in which a comparison was made between the number of monocytes and macrophages, there were many more monocytes than macrophages. This suggests that the movement of monocytes

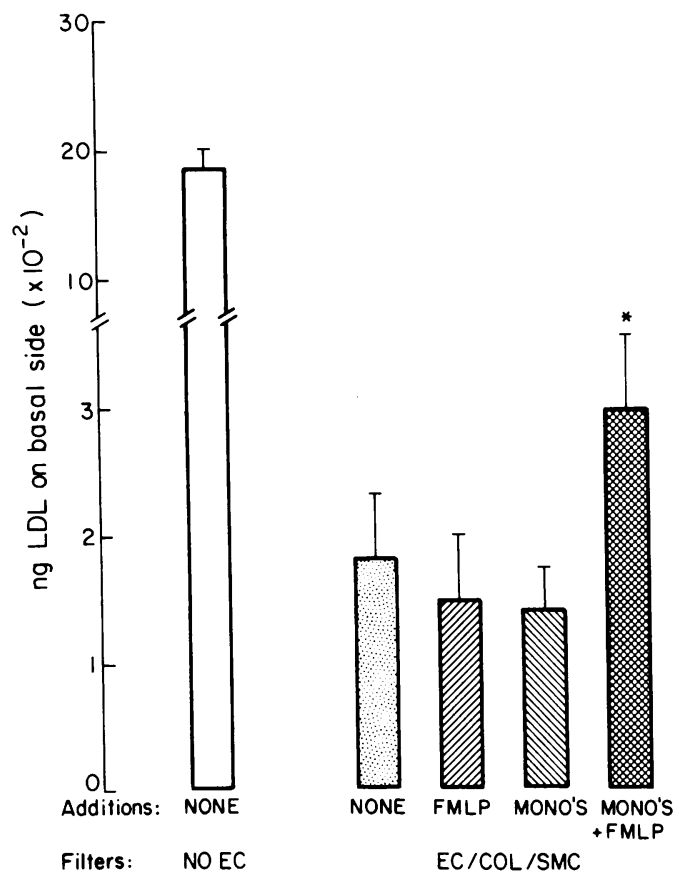

Figure 6. Transport of LDL across the multilayer in relation to monocyte migration. The media on the basal side of the preparations in the experiments described in Figs. 5 and 6 were removed and TCA-precipitable radioactivity was determined. The data represent mean \pm 1 SD of values from 4 to 12 preparations. ${ }^{*} P<0.001$. Abbreviations are the same as in Figs. 3-5. The increase in LDL transported to the basal side was statistically significant after monocyte diapedesis; however, the amount of the additional LDL transported was very small compared with that in the absence of an endothelial monolayer.

into and out of the intima may be a normal event, and under normal circumstances only a small number of these cells will be converted into macrophages in the artery wall (45). Gerrity and Schwartz (46), Mitchell and Schwartz (47), and Cornhill et al. (48) have demonstrated that atherosclerotic lesions develop at predictable sites in the arterial tree. These sites of increased monocyte adherence, diapedesis, and increased arterial permeability are sites of low shear stress (49-51). The conditions of our coculture may maximally exaggerate these conditions and may allow us to explain the mechanisms of the interactions between blood components and the cells of the artery wall.

\section{Acknowledgments}

We thank Dr. Judith A. Berliner and Dr. Mary C. Territo for valuable advice on chemotaxis, Faranak Elahi and Karin Sykes for their excellent technical assistance, Susan C. Murphy for the preparation of the manuscript, and the members of the University of California, Los Angeles Heart Transplant Team for collecting the aortic specimens.

This work was supported in part by the United States Public Health Services grants HL-30568, IT 32 HL-07412, and RR-865; the Laubisch Fund; and the M. K. Grey Fund.

\section{References}

1. Jones, P. 1979. Construction of an artificial blood vessel wall from cultured endothelial and smooth muscle cells. Proc. Natl. Acad. Sci. USA. 76:1882-1886. 
2. Merrilees, M. J., and L. Scott. 1981. Interaction of aortic endothelial and smooth muscle cells in culture. Effect on glycosaminoglycan levels. Atherosclerosis. 39:147-161.

3. Davies, P. F., G. A. Truskey, H. B. Warren, S. E. O'Connor, and B. H. Eisenhare. 1985. Metabolic cooperation between vascular endothelial cells and smooth muscle cells in co-culture: changes in low density lipoprotein metabolism. J. Cell Biol. 101:871-879, 1985.

4. Hajjar, D. P., D. J. Falcone, J. B. Amberson, and J. M. Heffon. 1985. Interaction of arterial cells. I. Endothelial cells alter cholesterol metabolism in co-cultured smooth muscle cells. J. Lipid Res. 26:1212-1223.

5. Hajjar, D. P., A. J. Marcus, and K. A. Hajjar. 1987. Interactions of arterial cells. Studies on the mechanisms of endothelial cell modulation of cholesterol metabolism in co-cultured smooth muscle cells. $J$. Biol. Chem. 262:6976-6981.

6. Weinberg, C. B., and E. Bell. 1986. A blood vessel model constructed from collagen and cultured vascular cells. Science. (Wash. DC). 231:397-400.

7. Taylor, R. F., T. H. Price, S. M. Schwartz, and D. C. Dale. 1981. Neutrophil-endothelial cell interactions on endothelial monolayers grown on micropore filters. J. Clin. Invest. 67:584-587.

8. Shasby, M. D., S. E. Lind, S. S. Shasby, J. C. Goldsmith, and G. W. Hunninghake. 1985. Reversible oxidant-induced increases in albumin transfer across cultured endothelium. Alterations in cell shape and calcium homeostasis. Blood. 65:605-614.

9. Territo, M., J. A. Berliner, and A. M. Fogelman. 1984. Effect of monocyte migration on low density lipoprotein transport across aortic endothelial cell monolayers. J. Clin. Invest. 74:2279-2284.

10. Stoll, L. L., and A. A. Spector. 1987. Lipid transfer between endothelial and smooth muscle cells in coculture. J. Cell. Physiol. 133:103-110.

11. Navab, M., G. P. Hough, J. A. Berliner, J. A. Frank, A. M. Fogelman, M. E. Haberland, and P. A. Edwards. 1986. Rabbit betamigrating very low density lipoprotein increases endothelial macromolecular transport without altering electrical resistance. J. Clin. Invest. 78:389-397.

12. Navab, M., G. P. Hough, B. J. Van Lenten, J. A. Berliner, and A. M. Fogelman. 1988. Low density lipoproteins transfer bacterial lipopolysaccharides across endothelial monolayers in a biologically active form. J. Clin. Invest. 81:601-605.

13. Colucci, W. S., T. A. Brock, M. A. Gimbrone, Jr., and R. W. Alexander. 1985. Nonlinear relationship between $\alpha$-adrenergic receptor occupancy and norepinephrine-stimulated calcium flux in cultured vascular smooth muscle cells. Mol. Pharmacol. 27:517-524.

14. Pitas, R. E., T. L. Innerarity, J. N. Weinstein, and R. W. Mahley. 1981. Acetoacetylated lipoproteins used to distinguish fibroblasts from macrophages in vitro by fluorescence microscopy. Arteriosclerosis. 1:177-185.

15. Gown, A. M., T. Tsukada, and R. Ross. 1986. Human atherosclerosis. II. Immunocytochemical analysis of the cellular composition of human atherosclerotic lesions. Am. J. Pathol. 125:191-207.

16. Thornton, S., S. N. Muller, and E. M. Levine. 1983. Human endothelial cells: use of heparin in cloning and long term serial cultivation. Science. (Wash. DC). 222:623-625.

17. Van Buul-Wortelboer, M. F., H. J. M. Brinkman, K. P. Dingemans, P. H. G. DeGroot, W. G. Van Aken, and J. A. Van Mourik. 1986. Reconstitution of the vascular wall in vitro. A novel method to study interactions between endothelial and smooth muscle cells. Exp. Cell. Res. 162:151-158.

18. Havel, R. J., H. A. Eder, and J. H. Bragdon. 1955. The distribution and chemical composition of ultracentrifugally separated lipoproteins of human serum. J. Clin. Invest. 43:1345-1353.

19. McFarlane, A. S. 1958. Efficient trace-labelling of proteins with iodine. Nature (Lond.). 182:53.

20. Bilheimer, D. W., S. Eisenberg, and R. I. Levy. 1972. The metabolism of very low density lipoproteins. I. Preliminary in vitro and in vivo observations. Biochim. Biophys. Acta. 260:212-221.
21. Lowry, O. H., M. J. Rosebrough, A. L. Farr, and R. J. Randall. 1951. Protein measurement with the Folin phenol reagent. J. Biol. Chem. 193:265-275.

22. Fogelman, A. M., M. E. Haberland, J. Seager, M. Hokom, and P. A. Edwards. 1981. Factors regulating the activities of the low density lipoprotein receptor and the scavenger receptor on human monocytemacrophages. J. Lipid Res. 22:1131-1141.

23. Fogelman, A. M., F. Elahi, K. Sykes, B. J. Van Lenten, M. C. Territo, and J. A. Berliner. 1988. Modification of the Recalde method for the isolation of human monocytes. J. Lipid Res. 29:1243-1247.

24. Spurr, A. R. 1969. A low viscosity epoxy resin embedding medium for electron microscopy. J. Ultrastruct. Res. 26:31-42.

25. Rhodin, J. A. G. 1980. Architecture of the vessel wall. In Handbook of Physiology: The Cardiovascular System II. Chapter 1. D. F. Bohr, A. P. Somlyo, and H. V. Sparks, Jr., editors. American Physiological Society, Bethesda, MD. 1-31.

26. Smith, E. B., and E. M. Staples. 1980. Distribution of plasma proteins across the human aortic wall. Barrier functions of endothelium and internal elastic lamina. Atherosclerosis. 37:579-590.

27. Chobanian, A. V., J. O. Menzoian, J. Shipman, K. Heath, and C. C. Haudenchild. 1983. Effects of endothelial denudation and cholesterol feeding on in vivo transport of albumin, glucose, and water across rabbit carotid artery. Circ. Res. 53:805-814.

28. Ramirez, C. A., C. K. Colton, K. A. Smith, M. B. Stemerman, and R. S. Lees. 1984. Transport of ${ }^{125} \mathrm{I}$-albumin across normal and deendothelialized rabbit thoracic aorta in vivo. Arteriosclerosis. 4:283-291.

29. O'Donnell, M. P., and F. F. Vargas. 1986. Electrical conductivity and its use in estimating an equivalent pore size for arterial endothelium. Am. J. Physiol. 250:H16-H21.

30. Pawlowski, N. A., E. L. Abraham, S. Pontier, W. A. Scott, and Z. A. Cohn. 1985. Human monocyte-endothelial cell interaction in vitro. Proc. Natl. Acad. Sci. USA. 82:8208-8212.

31. Bevilacqua, M. P., J. S. Pober, M. E. Wheeler, R. S. Cotran, and M. A. Gimbrone, Jr. 1985. Interleukin-1 activation of vascular endothelium. Effects on procoagulant activity and leukocyte adhesion. Am. J. Pathol. 121:393-403.

32. Migliorisi, G., E. Folkes, N. Pawlowski, and E. B. Cramer. 1987. In vitro studies of human monocyte migration across endothelium in response to leukotriene $\mathrm{B}_{4}$ and f-met-leu-phe. Am. J. Pathol. 127:157-167.

33. Furie, M. B., B. L. Naprstek, and S. C. Silverstein. 1987. Migration of neutrophils across monolayers of microvascular endothelial cells. An in vitro model of leukocyte extravasation. J. Cell. Sci. 88:161-175.

34. Poole, J. C. F., and H. W. Florey. 1958. Changes in the endothelium of the aorta and the behavior of macrophages in experimental atheroma of rabbits. J. Pathol. Bacteriol. 27:245-251.

35. Still, W. J. S., and P. R. Marriott. 1964. Comparative morphology of the early atherosclerotic lesion in man and cholesterol-atherosclerosis in the rabbit. An electromicroscopic study. J. Atheroscler. Res. 4:373-386.

36. Geer, J. C. 1965. Fine structure of human aortic intimal thickening and fatty streaks. Lab. Invest. 14:1764-1783.

37. Gerrity, R. G., H. K. Naito, M. Richardson, and C. J. Schwartz. 1979. Dietary induced atherogenesis in swine. Morphology of the intima in prelesion stages. Am. J. Pathol. 95:775-793.

38. Ross, R. 1986. The pathogenesis of atherosclerosis. An update. N. Engl. J. Med. 314:488-500.

39. Nash, S., J. Stafford, and J. L. Madara. 1987. Effects of polymorphonuclear leukocytes transmigrating on the barrier function of cultured intestinal epithelial monolayers. J. Clin. Invest. 80:11041113.

40. Berliner, J. A., M. Territo, L. Almada, A. Carter, E. Shafonsky, and A. M. Fogelman. 1985. Monocyte chemotactic factor produced by large vessel endothelial cells in vitro. Arteriosclerosis. 6:254-258.

41. Jauchem, J. R., M. Lopez, E. A. Sprague, and C. J. Schwartz. 
1982. Mononuclear cell chemoattractant activity from cultured arterial smooth muscle cells. Exp. Mol. Pathol. 37:166-174.

42. Mazzone, T., M. Jensen, and A. Chait. 1983. Human arterial wall cells secrete factors that are chemotactic for monocytes. Proc. Natl. Acad. Sci. USA. 80:5094-5097.

43. Joris, I., E. Stetz, and G. Majno. 1979. Lymphocytes and monocytes in the aortic intima. An electronmicroscopic study in the rat. Atherosclerosis. 34:221-231.

44. Freudenberg, N., and K. H. Riese. 1976. Characterization of cells of the normal aortic endothelium of adult rats and changes due to endotoxine shock. I. Communication: light microscopy, autoradiography, DNA cytophotometry and enzyme histochemistry. Beitr. Path. Bd. 159:125-142.

45. Duff, G. L., G. C. McMillan, and A. C. Ritchie. 1957. The morphology of early atherosclerotic lesions of the aorta demonstrated by the surface technique in rabbits fed cholesterol. Am. J. Pathol. 33:845-873.

46. Gerrity, R. G., and C. J. Schwartz. 1977. Structural correlates of arterial endothelial permeability in the Evans blue mode. Prog. Biochem. Pharmacol. 13:134-137.

47. Mitchell, A., Jr., and C. J. Schwartz. 1968. In Arterial Disease. Blackwell Scientific Publications, Ltd., Oxford, UK. 50-69.

48. Cornhill, J. F., W. A. Barrett, E. E. Herderick, R. W. Mahley, and D. L. Fry. 1985. Topographic study of Sudanophilic lesions in cholesterol-fed minipigs by image analysis. Arteriosclerosis. 5:415426.

49. Caro, C. G., J. M. Fitz-Gerald, and R. C. Schroter. 1971. Atheroma and arterial wall shear. Observation, correlation and proposal of a shear dependent mass transfer mechanism for atherogenesis. Proc. $R$. Soc. Lond. B Biol. Sci. 177:109-159.

50. Friedman, M. H., G. M. Hutchins, C. B. Bargeron, O. J. Deters, and F. F. Mark. 1981. Correlation between intimal thickness and fluid shear in human arteries. Atherosclerosis. 39:425-436.

51. Zarins, C. K., D. P. Giddens, B. K. Bharadvaj, V. S. Sottiurai, R. F. Mabon, and S. Glagov. 1983. Carotid bifurcation atherosclerosis. Quantitative correlation of plaque localization with flow velocity profiles and wall shear stress. Circ. Res. 53:502-514. 